\title{
Acquisition of Resistance to Sterol Demethylation Inhibitors by Populations of Venturia inaequalis
}

\author{
Stefan Kunz, Holger Deising, and Kurt Mendgen
}

Universität Konstanz, Fakultät für Biologie, Lehrstuhl für Phytopathologie, D-78434 Konstanz, Germany. Accepted for publication 28 August 1997.

\begin{abstract}
Kunz, S., Deising, H., and Mendgen, K. 1997. Acquisition of resistance to sterol demethylation inhibitors by populations of Venturia inaequalis. Phytopathology 87:1272-1278.

Acquisition of resistance to sterol demethylation inhibitors (DMIs) by populations of Venturia inaequalis was investigated using a microscopical method developed by C. Siebels and K. Mendgen. Microscopical analysis of conidiophore formation enabled the earlier detection of resistance and a clearer distinction between DMI-resistant and DMI-sensitive populations than other in vivo methods commonly used to analyze inhibitory effects of fungicides. In addition, because observations were made on the level of individuals, quantitative measures of the composition of conidial populations were obtained. The development of DMI sensitivity was followed over a period of 3 years in control apple orchards that had never

effective dose values determined by microscopical evaluation of conidiophore development for untreated populations revealed the baseline sensitivities of $0.3,0.96,0.09,1.22$, and $1.92 \mathrm{mg} / \mathrm{liter}$ for flusilazole, fenarimol, difenoconazole, tebuconazole, and pyrifenox, respectively. As compared with the baseline sensitivity, all populations with DMI history showed significant resistance to flusilazole. A strong nonlinear correlation $(R=$ 0.96) was found between the resistance factors and the sum of all DMI treatments of the 3 years before taking the sample. According to this correlation, resistance can be expected in all apple orchards of the fruitgrowing area along Lake Constance, Germany, in which more than two DMI treatments per season have been applied. Due to cross-resistance, the recently introduced DMI fungicides difenoconazole, tebuconazole, and pyrifenox did not allow the control of $V$. inaequalis populations resistant to flusilazole.
\end{abstract} been treated with fungicides and in orchards with DMI history. The $50 \%$
The success of modern, integrated disease control strategies strongly depends on the availability of efficient curative fungicides (2). Until 1995, sterol demethylation inhibitors (DMIs) were the only curative fungicides registered for use in apple orchards in Germany. Since DMI fungicides represent single-site inhibitors interfering with C-14 demethylation of 24-methylendihydrolanosterol in ergosterol biosynthesis $(6,18)$, a high risk of development of resistance exists (18). In fact, resistance problems have been observed in several pathogens including powdery mildews $(10,11,25)$, Penicillium digitatum (7), Pyrenophora teres (26), Sclerotinia homoeocarpa (9), and Venturia inaequalis (13). Isolates of $V$. inaequalis with reduced sensitivities to several DMI fungicides have been reported to occur worldwide $(4,13,23,24,31,32)$. Resistance to DMI fungicides is under multigenic control, increasing gradually by additive action of the different resistance genes $(6,15)$. Depending on the stringency of the selection pressure, sensitivity of $V$. inaequalis populations may, therefore, shift gradually from baseline sensitivity to a distinct level of resistance $(1,8,20)$. The exclusive and frequent use of DMI fungicides may thus lead to complete control failure in the field $(13,23)$.

The detection of insensitivities to DMI fungicides in isolates of V. inaequalis does not necessarily indicate DMI resistance. Significant variations of DMI sensitivity within populations that had never been treated with DMI fungicides have been described $(3,27,30)$.

While no resistance was detected in an American orchard after 12 years of extensive DMI application (30), complete control failure occurred in a Canadian orchard with a comparable number of DMI treatments $(13,16)$. This contradiction may be due to differences in infection pressure (16). In the fruit-growing area along

Corresponding author: K. Mendgen

E-mail address: kurt.w.mendgen@uni-konstanz.de

Publication no. P-1997-1029-01R

(C) 1997 The American Phytopathological Society
Lake Constance in southern Germany, high infection pressure exists and acquisition of DMI resistance by populations of $V$. inaequalis is likely to occur.

Siebels and Mendgen (28) have developed a microscopical in vivo method to evaluate the DMI sensitivity of the apple scab fungus on the population level. We used this method to study the time course of shifts in sensitivity to the DMI fungicide flusilazole in conidia and ascospores of different populations of $V$. inaequalis over a period of 3 years. Furthermore, the impact of the number of DMI treatments on the resistance factor and the sensitivity of $V$. inaequalis populations to DMI fungicides not yet registered for use in apple orchards in Germany were also investigated.

\section{MATERIALS AND METHODS}

Test plants. Potted apple trees (Malus domestica) of the cultivars Jonagold and Golden Delicious grafted on M 25 rootstocks at the Schweizerischen Forschungsanstalt für Obst und Weinbau, Wädenswil, Switzerland, were held in a greenhouse at 18 to $25^{\circ} \mathrm{C}$ and a $16-\mathrm{h}$ light period. The trees were fertilized weekly with $0.1 \%$ Hakaphos red $(\mathrm{N}-\mathrm{P}-\mathrm{K}=8: 12: 24)$ and 0.1\% Hakaphos blue (N-P-K = 15:10:15) (Compo GmbH, Münster, Germany).

Fungicides. The concentrations of the fungicides used in the sensitivity tests were based on the doses recommended by the manufacturer for use in the field. The recommended doses for flusilazole (Benocap-20 WP; Du Pont de Nemours GmbH, Bad Homburg, Germany), fenarimol (Rubigan-12 EC; Spiess \& Sohn, Kleinkarlbach, Germany), difenoconazole (Score-10 WG; Ciba Geigy AG, Basel, Switzerland), tebuconazole (Folicur-25 WP; Bayer AG, Leverkusen, Germany), and pyrifenox (Dorado-20 EC; Ciba Geigy AG, Frankfurt/M., Germany) were 25, 36, 25, 75, and $50 \mathrm{mg}$ active ingredient/liter, respectively.

Inocula. Inocula were obtained from nine different sampling sites. The location, apple cultivar, and fungicide history of the orchards are listed in Table 1. Orchard 1 was located about $60 \mathrm{~km}$ 
from the nearest conventionally managed apple orchard. All other orchards were situated in the fruit-growing area along Lake Constance. Orchard 2 was a test orchard of the University of Constance, where no pesticides are applied. Orchards 3, 4, 5, 6, 7, and 8 were commercial orchards treated in accordance with the guidelines of integrated production. Orchard 9 was part of a test orchard of the Amtliche Pflanzenschutzberatung Überlingen, where flusilazole was the only fungicide used from 1993 to 1995 . A minimum of 100 naturally infected leaves with sporulating scab lesions scattered over the whole orchard were collected per sample and stored in plastic bags at $-70^{\circ} \mathrm{C}$; the conidia were used for sensitivity tests. To obtain ascospores, naturally infected leaves were collected in November and overwintered in wire mesh cases on the ground of the orchard. The overwintered leaves were examined for development of pseudothecia, beginning at the end of February of the following year. Apple leaves with pseudothecia containing 5 to $10 \%$ mature ascospores were collected on 6 March 1995, and 22 April 1996, and stored in plastic bags at $-70^{\circ} \mathrm{C}$. To obtain ascospore suspensions, the leaves were thawed and incubated in a dark moist chamber for 10 days at $20^{\circ} \mathrm{C}$. Leaves containing mature, preconditioned pseudothecia were washed in deionized water for $10 \mathrm{~min}$ and placed upside down into a glass petri dish $(14.5 \mathrm{~cm}$ diameter) filled with $30 \mathrm{ml}$ of deionized water. The petri dish was illuminated from beneath with $1,800 \mathrm{~lx}$ for $1 \mathrm{~h}$ at $5^{\circ} \mathrm{C}$ to allow ascospore discharge into the water (29). Conidia or ascospores from one orchard collected during 1 day are referred to as a sample.

Conidia of many commercial orchards had a low germination rate. Thus, to obtain a sufficient number of fungal propagules, conidia from orchards 3, 4, 5, 6, 7, and 8 from 1994 and 1995 were used to inoculate nontreated apple trees. Inoculated plants were incubated at $18^{\circ} \mathrm{C}$ and $100 \%$ relative humidity in the dark for $24 \mathrm{~h}$. Thereafter, plants were kept in the greenhouse. Leaves with sporulating scab lesions containing multiplied conidia were collected after 14 to 20 days and stored in plastic bags at $-70^{\circ} \mathrm{C}$. Importantly, the dose-response relationships in multiplied conidia did not statistically differ from those of the original samples $(P=0.43$ for the sensitive sample [orchard 1] and $P=0.76$ for the resistant sample [orchard 9]).

Sensitivity test. Ten leaves with multiplied conidia or 50 naturally infected leaves with sporulating scab lesions were thawed and shaken in $100 \mathrm{ml}$ of deionized water to obtain conidial suspensions. Ascospore suspensions were produced as described above, using 20 leaves with mature pseudothecia. Conidial and ascospore suspensions were concentrated by centrifugation $(1,500 \times g$ for $10 \mathrm{~min}$ at $5^{\circ} \mathrm{C}$ ) or diluted with deionized water to yield a final concentration of $10^{5}$ spores $\mathrm{ml}^{-1}$ (spray inoculation) or $5 \times 10^{4}$ spores $\mathrm{ml}^{-1}$ (droplet inoculation). Only when at least $50 \mathrm{ml}$ of a spore suspension was available, test plants were spray-inoculated with a glass atomizer until runoff. If the spore suspension was less than $50 \mathrm{ml}$, droplets were placed onto the two youngest unfolded leaves of each shoot of the test plants. The inoculated plants were incubated in the dark at $18^{\circ} \mathrm{C}$ and $100 \%$ relative humidity for $24 \mathrm{~h}$. Different fungicide concentrations were applied by spraying the plants until runoff with a glass atomizer $28 \mathrm{~h}$ after inoculation using concentration ranges of 0.125 to $250 \mathrm{mg}$ of flusilazole/liter, 0.36 to $360 \mathrm{mg}$ of fenarimol/liter, 0.025 to $250 \mathrm{mg}$ of difenoconazole/liter, 0.25 to $750 \mathrm{mg}$ of tebuconazole/liter, and 0.5 to $500 \mathrm{mg}$ of pyrifenox/liter. Three shoots were used per treatment. Control shoots were sprayed with deionized water.

Subsequently, plants were incubated at $20^{\circ} \mathrm{C}$ and $80 \%$ relative humidity during the 15 -h light $(19,000 \mathrm{~lx})$ period and $14^{\circ} \mathrm{C}$ and $90 \%$ relative humidity during the 9 -h dark period. Six days after inoculation, the two youngest inoculated leaves per shoot were fixed in $1 \%$ (vol/vol) glutaraldehyde for $20 \mathrm{~min}$, bleached in acetic acid/ ethanol (4:96\% [vol/vol]) for $20 \mathrm{~h}$, boiled in lactic acid/glycerol/ ethanol $/ \mathrm{H}_{2} \mathrm{O}(8: 8: 66: 18 \%$ [ $\left.\mathrm{vol} / \mathrm{vol}]\right)$ for $10 \mathrm{~min}$, and incubated for at least $20 \mathrm{~h}$ in this solution. Thereafter, the leaves were placed on glass slides, covered with a piece of cotton cloth, and fixed with a wire frame and paper clips. The glass slides with the leaves were autoclaved for $15 \mathrm{~min}$ in $0.5 \mathrm{M} \mathrm{KOH}$ (14), washed three times with deionized water, and boiled in the staining solution containing $0.02 \%$ (wt/vol) methyl blue in lactic acid/glycerol/ethanol/ $\mathrm{H}_{2} \mathrm{O}$ (8:8:66:18\% [vol/vol]) for $10 \mathrm{~min}$. The leaves were then washed again with deionized water, the wire frame and the cotton cloth were removed, and the leaves were mounted in glycerol/lactic acid/ $\mathrm{H}_{2} \mathrm{O}$ (50:25:25\% [vol/vol]) and evaluated under a microscope at $200 \times$ magnification. One hundred infection sites were investigated on each leaf with respect to differentiation of conidiophores. An infection site was defined as a conidium or an ascospore differentiated up to the appressorium with a visible penetration pore. To calculate dose-response relationships, eight different leaves were analyzed per treatment.

This microscopical method was compared with two other methods frequently used to evaluate fungicide efficiencies, i.e., determination of the diseased leaf area and determination of the capacity of production of conidia. The diseased leaf area of the three youngest inoculated leaves was estimated 16 days after inoculation according to Dahmen and Staub (5). To measure conidia production, the three youngest inoculated leaves were shaken in $30 \mathrm{ml}$ of deionized water 16 days after inoculation. The conidial concentration was determined with a haematocytometer and based on the fresh weight of the leaves (5). Fungicide treatments were performed as described above. Thirty-six leaves per fungicide treatment were analyzed to calculate dose-response relationships.

Data analysis. Different dose-response relationships were statistically compared with a factorial analysis using ranks (21) with a macro written by W. Nagl, Universität Konstanz, under SAS (Statistical Analysis System; SAS Institute, Inc., Cary, NC) to evaluate actual differences. The averages of the efficiencies were logit-transformed (logit efficiency $=\ln ($ efficiency/1 - efficiency) $(22)$. Effi-

TABLE 1. Origin and fungicide history of the Venturia inaequalis populations used

\begin{tabular}{|c|c|c|c|c|c|c|c|c|c|c|c|}
\hline \multirow[b]{3}{*}{ Orchard } & \multirow[b]{3}{*}{ Location } & \multirow[b]{3}{*}{ Cultivar $^{\mathrm{a}}$} & \multirow[b]{3}{*}{ Year of planting } & \multicolumn{8}{|c|}{ Fungicide treatments ${ }^{\mathrm{b}}$} \\
\hline & & & & \multicolumn{2}{|c|}{1992} & \multicolumn{2}{|c|}{1993} & \multicolumn{2}{|c|}{1994} & \multicolumn{2}{|c|}{1995} \\
\hline & & & & DMI & Total & DMI & Total & DMI & Total & DMI & Total \\
\hline 1 & Öschingen & GD & 1980 & 0 & 0 & 0 & 0 & 0 & 0 & 0 & 0 \\
\hline 2 & Konstanz & GD & 1991 & 0 & 0 & 0 & 0 & 0 & 0 & 0 & 0 \\
\hline 3 & Kippenhausen & JG & 1991 & 2 & 15 & 1 & 15 & 6 & 21 & 1 & 21 \\
\hline 4 & Lindau & JG & 1981 & 3 & 16 & 4 & 15 & 8 & 15 & 0 & 17 \\
\hline 5 & Bodman & JG & 1987 & 4 & 12 & 2 & 9 & 1 & 15 & 0 & 17 \\
\hline 6 & Oberdorf & JG & 1980 & 7 & 15 & 4 & 15 & 8 & 20 & 0 & 24 \\
\hline 7 & Kleintobel & GD & 1969 & 5 & 18 & 6 & 16 & 1 & 16 & 4 & 18 \\
\hline 8 & Litzelstetten & GD & 1980 & 5 & 13 & 5 & 13 & 3 & 13 & 3 & 13 \\
\hline 9 & Überlingen & GD & 1990 & 5 & 19 & 12 & 12 & 11 & 11 & 14 & 14 \\
\hline
\end{tabular}

a Samples were taken from the cultivars Golden Delicious (GD) or Jonagold (JG).

$\mathrm{b}$ The number of sterol demethylation inhibitor (DMI) applications and the total number of fungicide treatments (total) in the respective year are given. Applications with triadimenol were not counted as DMI treatments because of the inefficiency of the compound against V. inaequalis. 

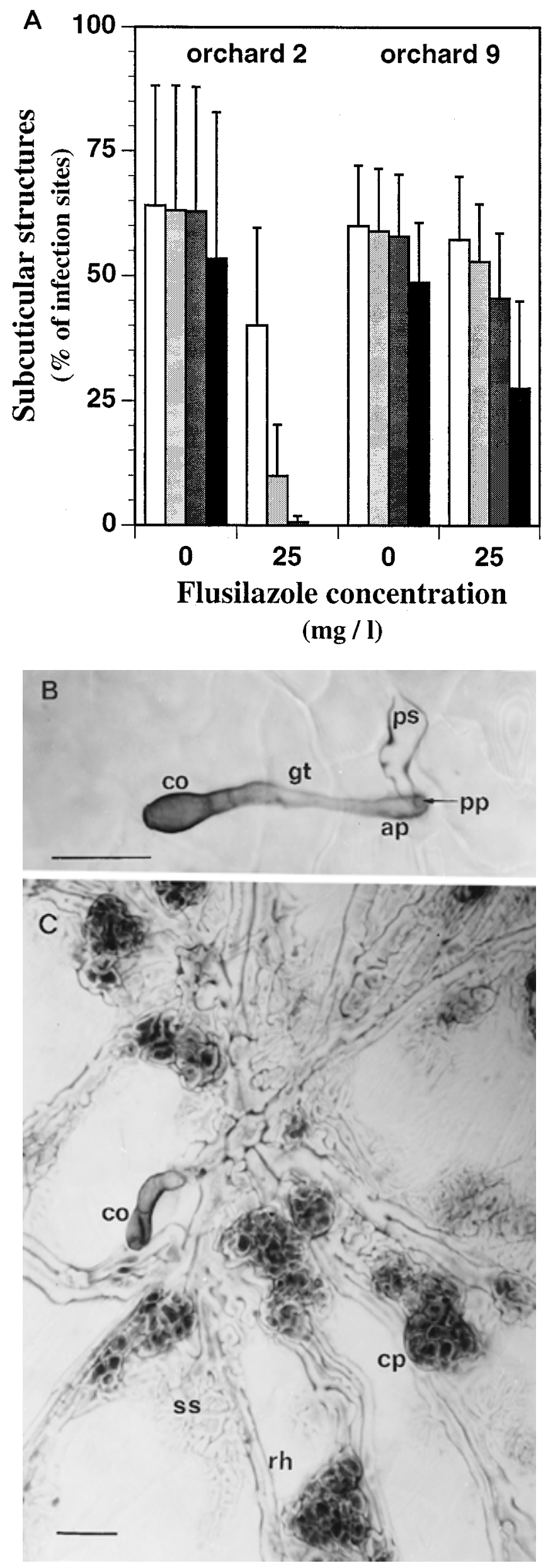

ciencies of $100 \%$ had to be modified before logit transformation. Modified efficiency $=1-1 / 2 n$, in which $n$ was the number of all infection sites in this treatment (22). A linear regression with the Regression program of "Statistica for Macintosh" (StatSoft, Inc., Tulsa, OK) between the logit-transformed efficiencies and the logarithm of the fungicide concentration revealed the $\mathrm{ED}_{50}$ value (fungicide concentration that gave $50 \%$ efficiency) of the sample. The resistance factor was calculated by dividing the $\mathrm{ED}_{50}$ value of the sample by the $\mathrm{ED}_{50}$ value of the baseline sensitivity. Nonlinear regression analyses were performed with the aid of the Nonlinear program of "Statistica for Macintosh" (StatSoft, Inc.).

\section{RESULTS}

Comparison of infection structure differentiation in DMIsensitive and DMI-resistant populations. The development of subcuticular structures from conidia of sensitive and resistant populations of $V$. inaequalis on water-treated control leaves and on leaves

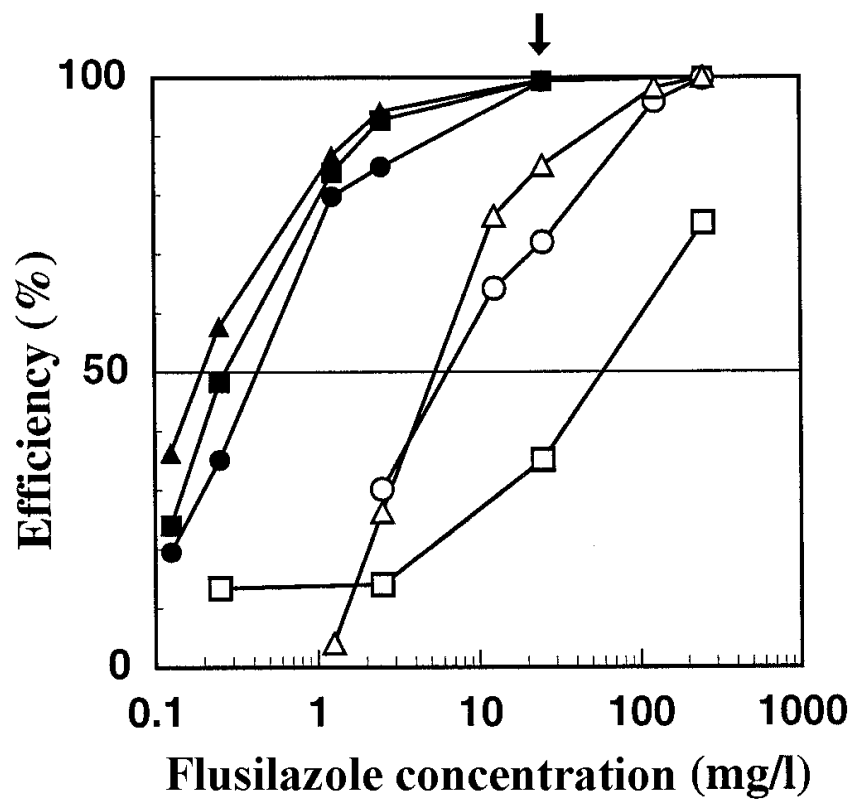

Fig. 2. Comparison of three different methods to determine sterol demethylation inhibitor (DMI) efficiency. Fungicide treatments were performed $28 \mathrm{~h}$ after inoculation with conidia of Venturia inaequalis. The efficiency of flusilazole was determined by microscopical analysis of conidiophore formation (squares) 6 days after inoculation by estimating the percentage of diseased leaf area (circles) or by counting conidia produced (triangles) 15 days after inoculation. Filled symbols represent flusilazole efficiencies determined with sensitive $V$. inaequalis populations, open symbols represent the respective values for a resistant population. The arrow indicates flusilazole concentration recommended in the field.

Fig. 1. Development of Venturia inaequalis on apple leaves treated with the sterol demethylation inhibitor (DMI) fungicide flusilazole. A sensitive conidial population from orchard 2 and a resistant population from orchard 9 were compared. Leaves were treated with water (0) or with $25 \mathrm{mg}$ of flusilazole/liter $28 \mathrm{~h}$ after inoculation, and fungal structures were evaluated 6 days after inoculation. A, Formation of fungal structures on control and fungicidetreated leaves. Eight leaves were evaluated per treatment. $\square=$ primary subcuticular stroma, $\square$ = runner hyphae, $\square$ = secondary subcuticular stroma, and $\square=$ conidiophores. Error bars indicate standard deviation. B, DMIsensitive conidium (co) from orchard 2 with germ tube (gt), appressorium (ap), and penetration hypha visible as the penetration pore (pp). After penetration of the cuticle, the subcuticular primary stroma (ps) is formed in the presence of $25 \mathrm{mg}$ of flusilazole/liter. C, DMI-resistant conidium from orchard 9 in addition to the structures seen in B, differentiated runner hyphae (rh), and the secondary stroma (ss) with conidiophores (cp) on a leaf treated with $25 \mathrm{mg}$ of flusilazole/liter. Bars are $20 \mu \mathrm{m}$. 
treated with flusilazole was compared 6 days after inoculation (Fig. 1). Sensitive and resistant fungal structures were indistinguishable on control leaves (Fig. 1A), but significant differences were seen after the application of $25 \mathrm{mg}$ of flusilazole/liter. While differentiation of the primary stroma was only slightly reduced, formation of the secondary stroma and of conidiophores was strongly inhibited in DMI-sensitive populations (Fig. 1A and B). In contrast, the resistant population was able to form conidiophores on flusilazoletreated leaves with high efficiency (Fig. 1A and C).

Comparison of different methods to evaluate fungicide sensitivity. In Figure 2, flusilazole sensitivities of a DMI-resistant population and DMI-sensitive control populations were compared using (i) microscopical analysis of conidiophores formed, (ii) the diseased area of the leaf, and (iii) the number of conidia released. The three methods used were statistically indistinguishable when baseline sensitivities were determined. With all three methods, fungicide efficiencies with untreated populations differed significantly $(P<$ 0.0005) from those of the population with DMI history. However, while measurement of diseased area and numbers of conidia formed gave indistinguishable efficiency curves for the resistant population, the microscopical analysis of conidiophores yielded a curve differing significantly from the former $(P<0.01)$. With recommended field concentrations of $25 \mathrm{mg}$ of flusilazole/liter, differences were much more distinct using microscopical analyses as compared with the other two methods tested (Fig. 2). As compared with the other two methods used here, microscopical analyses of conidiophore development indicated occurrence of resistance earlier and distinctions between DMI-resistant and DMI-sensitive populations were clearer. Furthermore, because observations were made on the level of individuals, the microscopical method could give quantitative measures of the share of resistant spores. Therefore, microscopy was used in all further experiments.

Sensitivity of $\boldsymbol{V}$. inaequalis populations to flusilazole. Samples from the control orchards 1 (conidia of 1993, 1994, and 1995 and ascospores of 1995) and 2 (conidia of 1994 and 95) were tested for sensitivity to flusilazole. The sensitivity tests yielded $\mathrm{ED}_{50}$

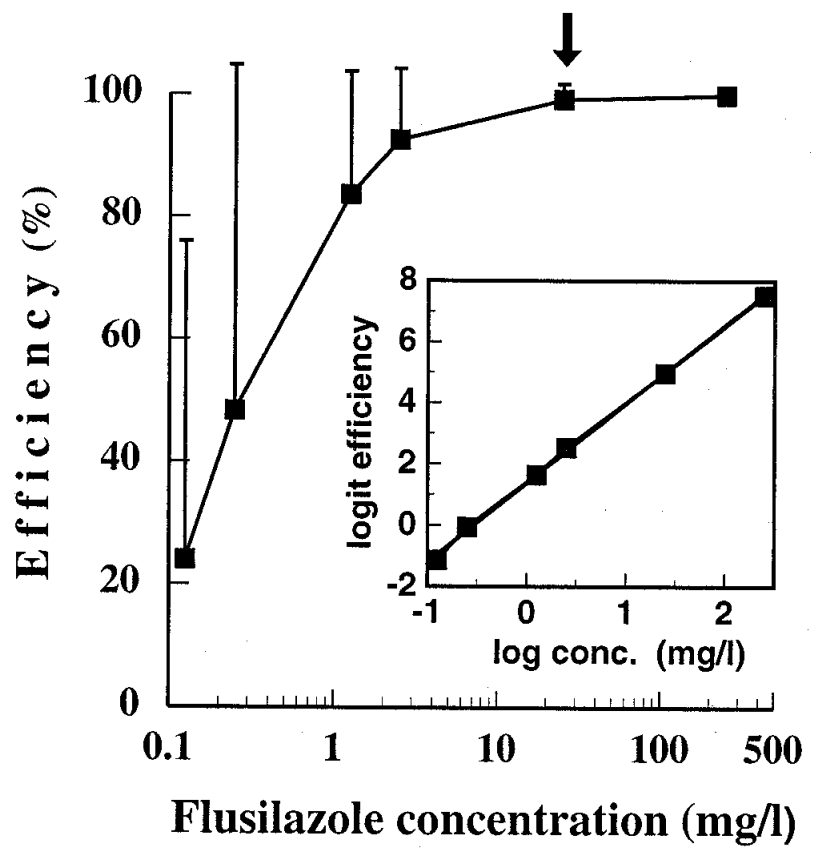

Fig. 3. Baseline sensitivity of Venturia inaequalis populations to flusilazole. Forty-eight leaves were evaluated for each fungicide concentration to yield dose-response relationships of sterol demethylation inhibitor (DMI)-sensitive populations. The arrow marks the flusilazole concentration recommended in the field. Error bars give the standard deviation between different leaves. The insert shows the regression line of the logit-transformed baseline sensitivity $(R=0.999)$. values between 0.21 and $0.59 \mathrm{mg} /$ liter. Since no significant difference $(P=0.44)$ between the dose-response relationships of the six samples was found, values were combined to determine the baseline sensitivity of $V$. inaequalis populations to flusilazole (Fig. 3). The combined efficiencies were logit-transformed, and the linear regression of the transformed efficiencies (Fig. 3, insert) revealed an $\mathrm{ED}_{50}$ of $0.3 \mathrm{mg}$ of flusilazole/liter as the baseline sensitivity.

The course of sensitivity to flusilazole was followed over a period of 3 years in three orchards differing in DMI history (Fig. 4). Orchard 3 was planted in 1991 and treated with DMI twice in 1992 and once in 1993. No significant resistance to flusilazole was found in conidia collected in 1993. In 1994, however, scab incidence was high in orchard 3 and six DMI applications were performed. Since resistance increased significantly (Fig. 4), scab control was unsatisfactory. DMI was applied only once in 1995, but resistance did not markedly decrease.

In orchard 4, three, four, and five DMI treatments were carried out in 1992, 1993, and 1994, respectively, and, consequently, conidia collected in 1994 showed pronounced resistance to flusilazole (Fig. 4). Ascospores were obtained from naturally infected leaves and tested for DMI sensitivity. The sexually formed ascospores of 1995 had a level of resistance similar to that of conidia collected in 1994 (Fig. 4), indicating that resistance was maintained in $V$. inaequalis after sexual reproduction. Although, in 1995, no DMI fungicides were applied in orchard 4, resistance did not decrease significantly in conidia of 1995 or in ascospores of 1996 (Fig. 4).

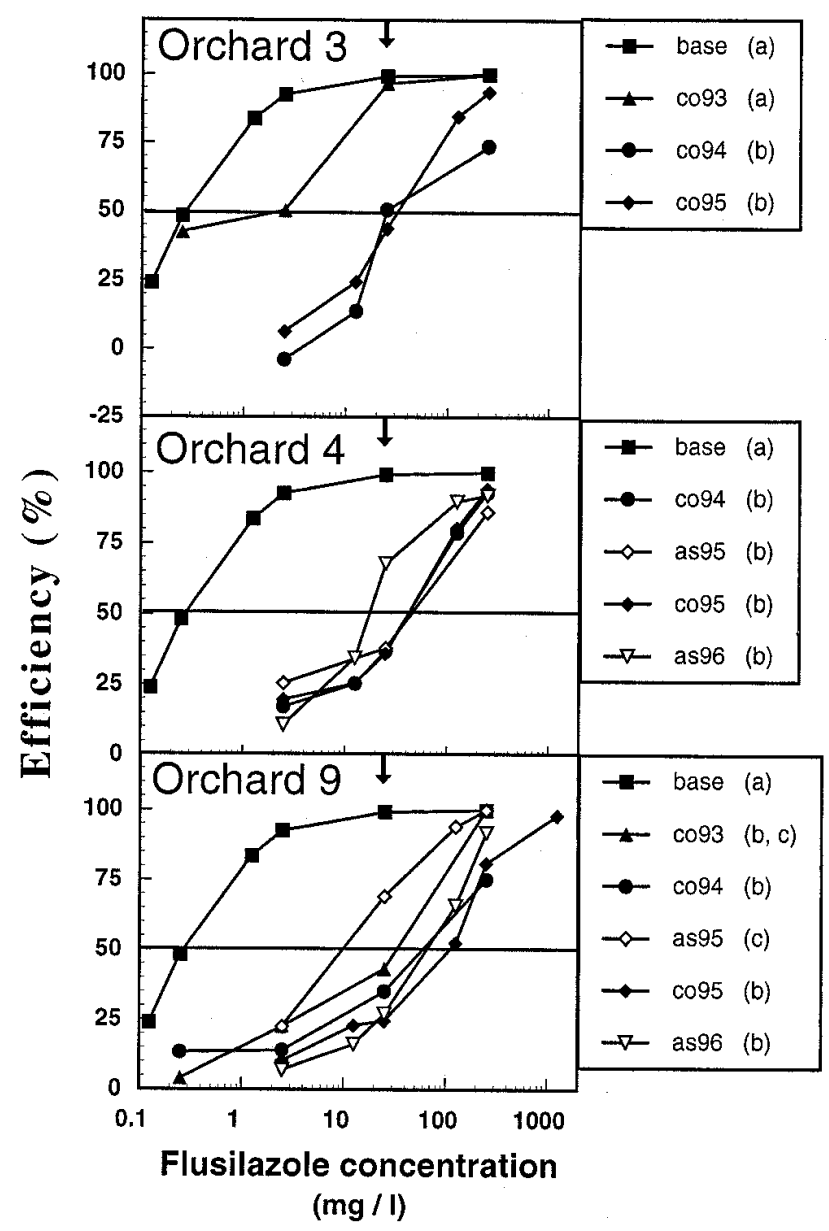

Fig. 4. Flusilazole sensitivity of Venturia inaequalis populations from orchards 3, 4, and 9. Dose-response relationships of conidia (co) and ascospores (as) from different years are shown in comparison to the baseline sensitivity (base). Eight leaves were evaluated per treatment. Different letters $(\mathrm{a}, \mathrm{b}$, and $\mathrm{c})$ in the legend indicate significant differences $(P<0.05)$ as determined with a factorial analysis using ranks. The arrow marks the flusilazole concentration recommended in the field. 
In orchard 9, only flusilazole was used for scab control from 1993 to 1995 . Within 3 years (from 1993 to 1995), the resistance factor in conidia increased from 35 to 161 (Table 2). However, ascospores of 1995 were more sensitive than conidia of 1994. Comparison of ascospores of 1996 with conidia of 1995 again indicated that resistance was maintained during sexual reproduction (Fig. 4).

To investigate whether the number of fungicide applications and the degree of resistance correlated, conidia from four additional orchards (orchards 5, 6, 7, and 8) differing in numbers of DMI treatments were tested for sensitivity to flusilazole in 1995. The samples listed in Table 2 showed varying levels of resistance as indicated by $\mathrm{ED}_{50}$ value and resistance factor. To test whether the different levels of resistance correlated with the total numbers of fungicide treatments or with the number of applications performed in the sampling year before sampling, nonlinear regression analyses were conducted. A total of 22 samples collected from nine orchards tested for sensitivity to flusilazole (Table 2$)$ fitted best $(R=0.96)$ to the nonlinear function log RF $=\left(a \times \mathrm{DMI}_{3}\right) /\left(b+\mathrm{DMI}_{3}\right)$, in which RF is the resistance factor and $\mathrm{DMI}_{3}$ is the sum of all DMI treatments in the year the sample was taken (until the sampling date) plus the DMI treatments of the two preceding years. The factors $a$ and $b$ were determined as 2.20 and 2.64 , respectively. The regression curve thus approached a maximum level, given by factor $a$ of the function. Therefore, a maximum resistance factor of 158 could be expected. This function allowed calculation of the expected re-

TABLE 2. Flusilazole resistance in Venturia inaequalis populations ${ }^{\mathrm{a}}$

\begin{tabular}{|c|c|c|c|c|c|c|}
\hline$\underline{\text { Sample }^{\mathrm{b}}}$ & $\mathrm{DMI}_{1}^{\mathrm{c}}$ & $\mathrm{DMI}_{3}{ }^{\mathrm{d}}$ & Efficiency $(\%)^{\mathrm{e}}$ & $\mathrm{ED}_{50}^{\mathrm{f}}$ & $\mathrm{RF}^{\mathrm{g}}$ & $P^{\mathrm{h}}$ \\
\hline Baseline $^{\mathrm{i}}$ & 0 & 0 & 99 & 0.3 & $\ldots$ & $\ldots$ \\
\hline \multicolumn{7}{|l|}{ Orchard 3} \\
\hline Co 1993 & 1 & 3 & 95 & 1.4 & 5 & 0.55 \\
\hline Co 1994 & 6 & 10 & 50 & 55.1 & 186 & $1.5 \times 10^{-11}$ \\
\hline Co 1995 & 1 & 9 & 44 & 28.4 & 96 & $4.4 \times 10^{-12}$ \\
\hline \multicolumn{7}{|l|}{ Orchard 4} \\
\hline Co 1994 & 5 & 12 & 37 & 26.4 & 89 & $4.4 \times 10^{-12}$ \\
\hline As 1995 & 8 & 15 & 39 & 22.4 & 76 & $2.6 \times 10^{-10}$ \\
\hline Co 1995 & 0 & 12 & 36 & 24.0 & 81 & $3.3 \times 10^{-11}$ \\
\hline As 1996 & 0 & 12 & 68 & 18.4 & 62 & $1.7 \times 10^{-13}$ \\
\hline \multicolumn{7}{|l|}{ Orchard 5} \\
\hline Co 1995 & 0 & 3 & 87 & 6.6 & 22 & $6.0 \times 10^{-7}$ \\
\hline \multicolumn{7}{|l|}{ Orchard 6} \\
\hline Co 1995 & 0 & 12 & 75 & 11.4 & 38 & $4.2 \times 10^{-7}$ \\
\hline \multicolumn{7}{|l|}{ Orchard 7} \\
\hline Co 1995 & 4 & 11 & 69 & 10.5 & 35 & $1.7 \times 10^{-7}$ \\
\hline \multicolumn{7}{|l|}{ Orchard 8} \\
\hline Co 1995 & 3 & 11 & 42 & 19.5 & 66 & $1.2 \times 10^{-10}$ \\
\hline \multicolumn{7}{|l|}{ Orchard 9} \\
\hline Co 1993 & 12 & 20 & 43 & 10.4 & 35 & $2.4 \times 10^{-6}$ \\
\hline Co 1994 & 7 & 24 & 35 & 29.4 & 131 & $6.2 \times 10^{-15}$ \\
\hline As 1995 & 11 & 28 & 69 & 9.4 & 32 & $3.4 \times 10^{-6}$ \\
\hline Co 1995 & 7 & 30 & 25 & 47.8 & 161 & $2.4 \times 10^{-14}$ \\
\hline As 1996 & 14 & 37 & 27 & 44.0 & 149 & $2.0 \times 10^{-14}$ \\
\hline
\end{tabular}

a To determine flusilazole resistance, apple leaves were treated with different fungicide concentrations $28 \mathrm{~h}$ after inoculation with conidia or ascospores from orchards with different sterol demethylation inhibitor (DMI) history. Eight leaves per treatment were evaluated by microscopical in vivo analysis of conidiophore formation 6 days after inoculation. Dose-response curves were calculated to characterize the samples.

${ }^{\mathrm{b}}$ Orchard number, spore type (conidia [Co] or ascospores [As]), and the year the sample was taken.

${ }^{c}$ Number of DMI treatments in the year the sample was taken before the sampling date. Treatments with triadimenol were disregarded.

${ }^{d}$ Number of DMI treatments in the year the sample was taken before the sampling date and in the two preceding years. Treatments with triadimenol were disregarded.

e The efficiency of $25 \mathrm{mg}$ of flusilazole/liter.

${ }^{\mathrm{f}}$ Fungicide dosage in milligrams/liter needed for $50 \%$ efficiency.

g Resistance factor

${ }^{\text {h }} P$ value after comparison of the efficiencies of $2.5,25$, and $250 \mathrm{mg}$ of flusilazole/liter to the baseline with a factorial analysis using ranks.

${ }^{i}$ Dose-response relationships of six samples from orchards 1 and 2 were combined to yield the baseline sensitivity. sistance factors for nontested populations based on the known number of DMI treatments of the last 3 years.

Sensitivity of $\boldsymbol{V}$. inaequalis populations to fenarimol. Conidia of $V$. inaequalis dating from 1993 and 1994 were collected from orchard 1 and tested for sensitivity to fenarimol. There was no significant difference $(P=0.54)$ between the dose-response relationships of the two samples, and they were combined for determination of the fenarimol baseline sensitivity. After logit transformation of the efficiencies, the linear regression revealed an $\mathrm{ED}_{50}$ of $0.96 \mathrm{mg}$ of fenarimol/liter as the baseline sensitivity. Three samples from orchards with DMI history and differing levels of sensitivity to flusilazole (conidia from orchard 3 collected in 1993 and conidia from orchard 9 collected in 1993 and 1994) were tested for sensitivity to fenarimol. The resistance factors were between two and six times higher than those for flusilazole. Even conidia dated 1993 from orchard 3, which were sensitive to flusilazole, showed significant resistance to fenarimol (Table 3). With the recommended dose of $36 \mathrm{mg}$ of fenarimol/liter, efficiencies below $90 \%$ were observed for the three samples (Table 3).

Cross-resistance to different DMI fungicides. While pyrifenox has been registered for use in German apple orchards since 1995, the DMI fungicides difenoconazole and tebuconazole are not certified for use in apple orchards in Germany. Therefore, these fungicides are excellent tools to test occurrence of cross-resistance. The baseline sensitivities for difenoconazole, tebuconazole, and pyrifenox were determined with conidia from orchard 1 of 1994. The $\mathrm{ED}_{50}$ values are given in Table 4 . The highest sensitivity was attributed to difenoconazole. The sensitivity of conidia collected in 1994 from orchard 9, where only flusilazole had been applied, was significantly reduced with respect to the baselines for all DMI fungicides tested (Table 4). Importantly, the DMI fungicides difenoconazole, tebuconazole, and pyrifenox had not previously been applied in orchard 9. These data indicated the existence of cross-resistance among populations of $V$. inaequalis to flusilazole and the new DMIs tested. Treatment of conidia of 1994 from orchard 9 with the commercially recommended doses revealed that all three DMI fungicides had efficiencies below 90\% (Table 4). The application of a 10-fold higher concentration of difenoconazole resulted in an efficiency of $99 \%$. However, a 10 -fold increased concentration of tebuconazole or pyrifenox resulted in efficiencies of only 91 and $60 \%$, respectively.

\section{DISCUSSION}

Commercial apple orchards of the fruit-growing area along Lake Constance have been treated with an average of 15 fungicide applications per season (12). Most of these treatments have been performed to control infections by the apple scab fungus $V$. inaequalis.

TABLE 3. Resistance of Venturia inaequalis populations to fenarimol ${ }^{\mathrm{a}}$

\begin{tabular}{lcccc}
\hline Sample $^{\mathrm{b}}$ & ${\text { Efficiency }(\%)^{\mathrm{c}}}^{\mathrm{n}}$ & $\mathrm{ED}_{50}{ }^{\mathrm{d}}$ & Resistance factor & $P$ value $^{\mathrm{e}}$ \\
\hline $\begin{array}{l}\text { Baseline } \\
\text { Orchard 3 }\end{array}$ & 100 & 0.96 & & \\
$\quad$ Co 1993 & 72 & 29.5 & 31 & $9.9 \times 10^{-4}$ \\
Orchard 9 & & & & \\
$\quad$ Co 1993 & 9 & 144 & 151 & $4.5 \times 10^{-5}$ \\
Co 1994 & 14 & 236.4 & 247 & $8.4 \times 10^{-9}$ \\
\hline
\end{tabular}

a To determine fenarimol resistance, apple leaves were treated with different fungicide concentrations $28 \mathrm{~h}$ after inoculation with conidia from orchards with different sterol demethylation inhibitor (DMI) history. Eight leaves per treatment were evaluated by microscopical in vivo analysis of conidiophore formation 6 days after inoculation. Dose-response curves were calculated to characterize the samples.

b Orchard and the year the sample (conidia, Co) was taken.

c The efficiency of $36 \mathrm{mg} /$ liter of fenarimol.

${ }^{\mathrm{d}}$ Fungicide dosage in milligrams/liter needed for $50 \%$ efficiency.

e $P$ value after comparison of dose-response relationships of the sample with the baseline sensitivity (factorial analysis using ranks).

f The baseline sensitivity for fenarimol includes two samples from orchard 1. 
Great efforts have been made to reduce the number of fungicide treatments. This has been accomplished by integrated disease control strategies, combining indirect measures such as summer pruning and orchard sanitation with curative fungicide treatments after infection periods (2). Infection periods are defined based on climatic data, ascospore release, and presence of susceptible tissue. Such strategies have allowed adequate scab control with three to four fungicide applications (2). However, the success of such strategies strongly depends on the availability of efficient curative fungicides such as DMIs.

To investigate the effect of frequencies of flusilazole treatments on DMI resistance, six samples of two $V$. inaequalis populations never treated with fungicides were used to evaluate the baseline sensitivity. The finding of slight differences in sensitivity between $V$. inaequalis populations is in good agreement with other reports $(3,19,27,30)$. Pronounced differences in baseline sensitivities can be found, depending on the method used. In vivo assays involving the host lead to higher $\mathrm{ED}_{50}$ values than in vitro assays performed on agar plates. Comparing the baseline sensitivities to flusilazole, fenarimol, and pyrifenox determined by the microscopical in vivo assay (this work) with values determined by in vitro assays (17) showed 24- to 64-fold higher baseline sensitivities in in vivo tests, depending on the fungicide used.

Significant resistance to flusilazole was found in almost all samples from orchards with DMI history. The resistance was highly correlated with the number of DMI treatments during the 3 years before taking the sample. This correlation describes the selection performed by fungicide application. With the exception of the powdery mildew-specific fungicide triadimenol that has no effect on apple scab, all DMI fungicides (flusilazole, penconazole, fenarimol, and myclobutanil) used in the orchards were assumed to apply comparable selection pressure, especially since more than $60 \%$ of all DMI treatments in the commercial orchards tested were performed with flusilazole. This assumption, however, may not be perfectly fulfilled, due to varying intrinsic activities of the different DMIs. There is evidence that high disease pressure may be an important driving force of resistance selection (16). Based on this assumption, the correlation between resistance factor and the number of DMI treatments can only be expected if samples are collected from an area with similar disease pressure. In our study, this is the case, since the fruit-growing area along Lake Constance has been shown

TABLE 4. Cross-resistance to different sterol demethylation inhibitor (DMI) fungicides in Venturia inaequalis populations ${ }^{\mathrm{a}}$

\begin{tabular}{|c|c|c|c|c|}
\hline Sample ${ }^{b}$ & Flusilazole & $\begin{array}{l}\text { Difeno- } \\
\text { conazole }\end{array}$ & $\begin{array}{l}\text { Tebu- } \\
\text { conazole }\end{array}$ & Pyrifenox \\
\hline \multicolumn{5}{|l|}{ Baseline $^{c}$} \\
\hline Efficiency $(\%)^{\mathrm{d}}$ & 99.3 & 100 & 100 & 100 \\
\hline $\mathrm{ED}_{50} \mathrm{e}$ & 0.30 & 0.09 & 1.22 & 1.92 \\
\hline \multicolumn{5}{|l|}{ Orchard 9 Co 1994} \\
\hline Efficiency (\%) & 35 & 82 & 31 & 35 \\
\hline $\mathrm{ED}_{50}$ & 39.0 & 5.4 & 195.0 & 112.2 \\
\hline Resistance factor & 132 & 59 & 160 & 58 \\
\hline$P$ value $\mathrm{f}^{\mathrm{f}}$ & $6.2 \times 10^{-15}$ & $2.7 \times 10^{-7}$ & $4.7 \times 10^{-7}$ & $9.6 \times 10^{-9}$ \\
\hline
\end{tabular}

a An apple scab population resistant to flusilazole was used to determine sensitivity to different DMI fungicides that had not previously been applied. Apple leaves were treated with different concentrations of difenoconazole, tebuconazole, and pyrifenox $28 \mathrm{~h}$ after inoculation with $V$. inaequalis conidia. Eight leaves per treatment were evaluated by microscopical in vivo analysis of conidiophore formation 6 days after inoculation. Doseresponse curves were calculated to characterize the samples.

b Orchard and the year the sample (conidia, Co) was taken.

c The baseline sensitivity for flusilazole includes six samples from orchard 1 and 2. For difenoconazole, tebuconazole, and pyrifenox, the baseline sensitivity includes one sample from orchard 1.

$\mathrm{d}$ The efficiency of the fungicide dosage recommended for the field $(25,25,75$, and $50 \mathrm{mg} / \mathrm{liter}$ for flusilazole, difenoconazole, tebuconazole, and pyrifenox).

e Fungicide dosage in milligrams/liter needed for $50 \%$ efficiency.

f $P$ value after comparison of dose-response relationships of the sample with the baseline sensitivity (factorial analysis using ranks). to be homogenous with respect to $V$. inaequalis disease pressure in the primary season. Because the test orchards used were distributed over the entire fruit-growing area along Lake Constance, the mathematical model correlating resistance and the number of DMI applications during the last 3 years could well be applied to other orchards of this area. The equation allows the prediction that DMI resistance would occur as soon as 3 years after introduction of the fungicide, and this prediction has been verified in orchard 3. The short time required to build up significant resistance levels may be due to the fact that DMI fungicides have been used in this area since 1985. In contrast to our findings, it took 7 years of fungicide application to induce resistance in a Canadian orchard (13). This clearly indicates that the equation presented here cannot be applied to other fruit-growing regions.

The equation allows the calculation of a maximal resistance factor approaching 158. The assumption that, in $V$. inaequalis, the fungicide dosage applied in the field represents the resistancestabilizing factor is consistent with the results presented here. In a population characterized by a resistance factor of 161 (orchard 9, conidia of 1995), $75 \%$ of the conidia gave rise to conidiophores on leaves treated with $25 \mathrm{mg}$ of flusilazole/liter (Fig. 4, Table 2). Thus, increasing the fungicide dosage would lead to increasing selection pressure that, in turn, would likely cause shifts towards higher levels of resistance. Likewise, the introduction of new DMI fungicides with higher intrinsic activity will also increase the selection pressure and induce higher levels of resistance.

Different DMI fungicides vary greatly with regard to intrinsic activities (16). The ranking of intrinsic activities against $V$. inaequalis, as indicated by baseline sensitivities, was difenoconazole $>$ flusilazole $>$ fenarimol $>$ tebuconazole $>$ pyrifenox. The finding that flusilazole has a higher intrinsic activity than fenarimol is in agreement with earlier reports $(28,30,32)$, and as a result, higher resistance factors were found for fenarimol as compared with flusilazole (32). This could explain the control failure occurring in the field with fenarimol in populations in which flusilazole was fully effective (23). Likewise, in our studies, conidia from orchard 3 dating from 1993 showed significant resistance to fenarimol, whereas they were sensitive to flusilazole. Thus, new DMIs with higher intrinsic activity may have lower resistance factors, and populations resistant to flusilazole could possibly be controlled with such fungicides. Of the DMIs examined, only difenoconazole had a higher intrinsic activity than flusilazole. Although one could expect high efficiency of this fungicide, sufficient control of apple scab was not achieved in our experiments. Cross-resistance was also detected for tebuconazole and pyrifenox, both of which had not been used in this region. We would thus expect that an introduction of these three fungicides in orchards with $V$. inaequalis populations resistant to flusilazole would not result in satisfactory scab control.

\section{ACKNOWLEDGMENTS}

This work was supported by the Ministry of Agriculture of BadenWürttemberg, Germany, and by the Fonds der chemischen Industrie. We thank E. Lange and P. Triloff for help in selecting the apple orchards and W. Nagl for help with the statistical analyses.

\section{LITERATURE CITED}

1. Braun, P. G., and McRae, K. B. 1992. Composition of a population of Venturia inaequalis resistant to myclobutanil. Can. J. Plant Pathol. 14: 215-220.

2. Bühler, M., and Gessler, C. 1994. First experiences with an improved apple scab control strategy. Norw. J. Agric. Sci. Suppl. 17:229-240.

3. Carisse, O., and Pelletier, J. R. 1994. Sensitivity distribution of Venturia inaequalis to fenarimol in Québec apple orchards. Phytoprotection 75:35-43.

4. Creemers, P., Vandergeten, J., and Vanmechelen, A. 1988. Variability in sensitivity of field isolates of Venturia sp. to demethylation inhibitors. Meded. Fac. Landbouwwet. Rijksuniv. Gent 53:577-587.

5. Dahmen, H., and Staub, T. 1992. Protective, curative, and eradicant activity of difenoconazole against Venturia inaequalis, Cercospora ara- 
chidicola, and Alternaria solani. Plant Dis. 76:774-777.

6. DeWaard, M. A. 1993. Recent developments in fungicides. Pages 11-19 in: Modern Crop Protection: Developments and Perspectives. J. C. Zadoks, ed. Wageningen Pers, Wageningen, the Netherlands.

7. Eckert, J. W., Sievert, J. R., and Ratnayake, M. 1994. Reduction of imazalil effectiveness against citrus green mold in California packinghouses by resistant biotypes of Penicillium digitatum. Plant Dis. 78:971-974.

8. Fiaccadori, R., Gielink, A. J., and Dekker, J. 1987. Sensitivity to inhibitors of sterol biosynthesis in isolates of Venturia inaequalis from Italian and Dutch orchards. Neth. J. Plant Pathol. 93:285-287.

9. Golembiewski, R. C., Vargas, J. M., Jr., Jones, A. L., and Detweiler, A. R. 1995. Detection of demethylation inhibitor (DMI) resistance in Sclerotinia homoeocarpa populations. Plant Dis. 79:491-493.

10. Gubler, W. D., Ypema, H. L., Ouimette, D. G., and Bettiga, L. J. 1996. Occurrence of resistance in Uncinula necator to triadimefon, myclobutanil, and fenarimol in California grapevines. Plant Dis. 80: 902-909.

11. Heaney, S. P. 1988. Populations dynamics of DMI fungicide sensitivity changes in barley powdery mildew. Pages 79-88 in: Fungicide Resistance in North America. C. J. Delp, ed. The American Phytopathological Society, St. Paul, MN.

12. Hellmann, M., and Sessler, B. 1995. Betriebsheftauswertung 1991-1993 in der integrierten Produktion von Kernobst in Baden-Württemberg. Erwerbsobstbau 78:78-81.

13. Hildebrand, P. D., Lockhart, C. L., Newberry, R. J., and Ross, R. G. 1988. Resistance of Venturia inaequalis to bitertanol and other demethylation-inhibiting fungicides. Can. J. Plant Pathol. 10:311-316.

14. Hood, M. E., and Shew, H. D. 1996. Applications of KOH-aniline blue fluorescence in the study of plant-fungal interactions. Phytopathology 86:704-708.

15. Kalamarakis, A. E., DeWaard, M. A., Ziogas, B. N., and Georgopoulos, S. G. 1991. Resistance to fenarimol in Nectria haematococca var. cucurbitae. Pestic. Biochem. Physiol. 40:212-220.

16. Köller, W. 1995. Managing resistance to sterol demethylation inhibitors. Pages 340-349 in: Proc. Int. Congr. Pestic. Chem., 8th. N. N. Ragsdale, ed. American Chemical Society, Washington, DC.

17. Köller, W., Parker, D. M., and Reynolds, K. L. 1991. Baseline sensitivities of Venturia inaequalis to sterol demethylation inhibitors. Plant Dis. 75:726-728.

18. Köller, W., and Scheinpflug, H. 1987. Fungal resistance to sterol bio- synthesis inhibitors: A new challenge. Plant Dis. 71:1066-1074.

19. Köller, W., Smith, F. D., Reynolds, K. L., Wilcox, W. F., and Burr, J. A. 1995. Seasonal changes of sensitivities to sterol demethylation inhibitors in Venturia inaequalis. Mycol. Res. 99:689-692.

20. Köller, W., Wilcox, W. F., Barnard, J., Jones, A. L., and Braun, P. G. 1997. Detection and quantification of resistance of Venturia inaequalis populations to sterol demethylation inhibitors. Phytopathology 87:184-190.

21. Meddis, R. 1984. Statistics Using Ranks: A Unified Approach. Basil Blackwell Publisher Ltd., Oxford, United Kingdom.

22. Neter, J., Wassermann, W., and Kutner, M. H. 1983. Applied Linear Regression Models. Richard D. Irwin, Inc., Homewood, IL.

23. Nowacka, H. 1991. A decrease of Venturia inaequalis (Cke) Aderh. sensitivity to fenarimol. Fruit Sci. Rep. 18:139-142.

24. Parisi, L., Guillaumès, J., and Wuster, G. 1994. Variabilité de la sensibilité au fénarimol de souches de Venturia inaequalis provenant de vergers francais. Agronomie 14:387-394.

25. Schepers, H. T. A. M. 1985. Changes during a three-year period in the sensitivity to ergosterol biosynthesis inhibitors of Sphaerotheca fuliginea in the Netherlands. Neth. J. Plant Pathol. 91:105-118.

26. Sheridan, J. E., Grbavac, N., and Sheridan, M. H. 1985. Triadimenol insensitivity in Pyrenophora teres. Trans. Br. Mycol. Soc. 85:338-341.

27. Sholberg, P. L., and Haag, P. D. 1993. Sensitivity of Venturia inaequalis isolates from British Columbia to flusilazole and myclobutanil. Can. J. Plant Pathol. 15:102-106.

28. Siebels, C., and Mendgen, K. 1994. A microscopic evaluation of the sensitivity of Venturia inaequalis populations to sterol demethylation inhibitors. Mycol. Res. 98:619-624.

29. Smereka, K. J., MacHardy, W. E., and Kausch, A. P. 1987. Cellular differentiation in Venturia inaequalis ascospores during germination and penetration of apple leaves. Can. J. Bot. 65:2549-2561.

30. Smith, F. D., Parker, D. M., and Köller, W. 1991. Sensitivity distribution of Venturia inaequalis to the sterol demethylation inhibitor flusilazole: Baseline sensitivity and implications for resistance monitoring. Phytopathology 81:392-396.

31. Stanis, V. F., and Jones, A. L. 1985. Reduced sensitivity to sterol-inhibiting fungicides in field isolates of Venturia inaequalis. Phytopathology 75:1098-1101.

32. Thind, T. S., Clerjeau, M., and Olivier, J. M. 1986. First observation on resistance in Venturia inaequalis and Guignardia bidwellii to ergosterolbiosynthesis inhibitors in France. Br. Crop Prot. Conf. 2:491-498. 